\title{
An investigation into the swash plate vibration and pressure pulsation of piston pumps based on full fluid-structure interactions*
}

\author{
Xiao-ping OUYANG ${ }^{\dagger}$, Xu FANG, Hua-yong YANG \\ (The State Key Laboratory of Fluid Power and Mechatronic Systems, Zhejiang University, Hangzhou 310027, China) \\ ${ }^{\dagger}$ E-mail: ouyangxp@zju.edu.cn \\ Received Oct. 26, 2015; Revision accepted Jan. 18, 2016; Crosschecked Feb. 22, 2016
}

\begin{abstract}
In this paper, dynamic analyses of the swash plate vibration and pressure pulsation of an aircraft piston pump based on fluid-structure interactions (FSIs) are presented. Models of the swash plate piston pumps with three FSIs (named full FSIs and non FSI) are given. The simulation results of the discharge pressures at different rotation speeds in the synthesized pump model and experiments show good agreement. The numerical simulation results of the forces on the swash plate and the flow rate of the outlet chamber are presented and compared. The results of the two models show that the discharge pressure pulsation mostly depends on the kinematic relations of the piston slipper-shoe units (FSI-1), and is almost isolated from the swash plate vibration. The full FSIs simulation shows that the swash plate vibration is strongly influenced by the pressure pulsation through the control actuator mechanism (FSI-2) and the control valve mechanism (FSI-3), but the non FSI model does not show the same result. The full FSIs model is much more accurate in predicting the vibration of the swash plate and the pulsation of the discharge pressure than the non FSI model.
\end{abstract}

Key words: Vibration, Pulsation, Swash plate, Aircraft, Piston pump, Fluid-structure interaction (FSI) http://dx.doi.org/10.1631/jzus.A1500286

CLC number: TH137.51

\section{Introduction}

The pressure-compensated axial-piston pump is one of the key components of aircraft hydraulic systems. High rotation speed and high discharge pressure are two of the most important characteristics of such pumps, and are liable to lead to high pressure pulsation and swash plate vibration. High pressure pulsation and swash plate vibration cause low efficiency and high noise, even failure of the aircraft pump and the hydraulic system. As the trend in pump design is gradually moving towards high efficiency

\footnotetext{
${ }^{*}$ Project supported by the National Natural Science Foundation of China (No. 51275450), the National Basic Research Program of China (973 Program) (No. 2014CB046403), and the Science Fund for Creative Research Groups of National Natural Science Foundation of China (No. 51521064)

(DD ORCID: Xiao-ping OUYANG, http://orcid.org/0000-0002-20907123; Xu FANG, http://orcid.org/0000-0001-7756-4371

(C) Zhejiang University and Springer-Verlag Berlin Heidelberg 2016
}

and low noise (Yang and Pan, 2015), it is necessary to keep both pressure pulsation and swash plate vibration as low as possible. The pulsation and vibration are very complicated, and are affected by the structure, the fluid, and the fluid-structure interactions (FSIs). The effects of the structure include the motions of the pistons, the swash plate, the control actuator, and the control valve mechanism. The effects of the fluid concern many variable or invariable fluid chambers and orifices in the pump. The FSIs include the mechanical vibration caused by pressure pulsation and the flow fluctuation accompanied by mechanical vibration. To a simulationbased technique for identifying key relationships between the pressure pulsation and the mechanical vibration, this paper presents two numerical models for investigating the inherent parameters of the pump.

In the field of flow fluctuation and pressure pulsation of piston pumps, Manring (2000) derived closed-form expressions to describe the 
characteristics of the flow ripple. The ripple amplitude and the pulse frequency of the flow ripple were determined by considering the fluid compressibility and the pump leakage. The fluid compressibility, viscosity, and the leakage flow rate have been analysed (Xu et al., 2015a). A new design method for the transition region of a valve plate based on the matching of flow area and the reduction of transient reverse flow has been introduced, which can be used in the design of a low-noise open circuit axial piston pump (Xu et al., 2015b). Investigations of the influence of liquid viscosity on the variable capacity displacement pump volumetric losses have been carried out (Koralewski, 2011). The barrel-port plate film thickness and barrel dynamics of a piston pump were studied by Bergada et al. (2012), considering the effect of oil pressure and temperature. The flow ripple was examined by Wang and Johnston (2009) and Johnston and Drew (1996). Huang et al. (2015) developed a model to investigate the characteristics of pressure pulsations in a combination of a variable displacement and speed-variable pump.

The mechanical vibration of the piston pump has been studied previously. Chen et al. (2006) used a system model to analyse the dynamic vibration of a swash plate type water hydraulic motor. The simulation revealed the vibration characteristics of each component in the motor. However, the research object was a fixed displacement pump, in which the motion of the swash plate was not contained, and the simulation model did not contain the fluid system and the FSIs. Manring and Mehta (2011) showed by a linearised model that reducing the swept volume of the control actuator and increasing the flow gain of the control valve was the most effective way to increase the bandwidth frequency of a piston pump. A kinematic model of a bent-axis pump has been created to predict the variations of the angular velocities and accelerations of the parts of the pump, with the acceleration of the swash plate angle considered as an idealised steady input (Abuhaiba and Olson, 2010). Bahr et al. (2003) built a model to study the vibration of an electrically constant power controlled piston pump with the angle of the swash plate employed to value the vibration characteristics. Analytical analysis of torque and forces at different fixed angles was conducted to verify the motion of the swash plate of an axial piston pump/motor (Norhirni et al., 2011). A structural finite element model was built by Meher and Rao (2006) for the optimal foundation design of a vertical pump assembly containing a pump, a motor, and their brackets.

The mechanical vibration of the swash plate and the discharge pressure pulsation are both inherent characteristics of the piston pump. Many previous investigations focused on one factor alone. However, in reality the two factors affect each other, the FSIs cannot be ignored in a dynamic analysis of the pressure pulsation and the swash plate vibration of the piston pump.

\section{Theoretical models}

Fig. 1 shows the structure of a pressure compensated axial-piston pump. It can be broadly divided into six parts, namely, the drive-shaft/cylinder assembly, the piston/slipper-shoe units, the swash plate, the control valve, the control actuator and the related accessories including the pump-housing and valve-plate. During operation, an external motor rotates the drive-shaft/cylinder assembly (at speed $\omega$ ), and hence the piston (area $A_{\mathrm{p}}$, mass $m_{\mathrm{p}}$ ) and slippershoe units. Pressing against the inclined plate, the rotating drive-shaft motion is transformed into a translational piston motion parallel to the shaft. The inclinational angle $\varphi$ of the swash plate, which is adjusted for the pump flow rate, can be angularly positioned by manipulating the control actuator (area $A_{\mathrm{a}}$, mass $m_{\mathrm{a}}$ ) against a bias spring (stiffness $k_{\mathrm{b}}$ ) positioned parallel to the shaft axis at a distance $l$. However, nonlinear influences, such as the changing

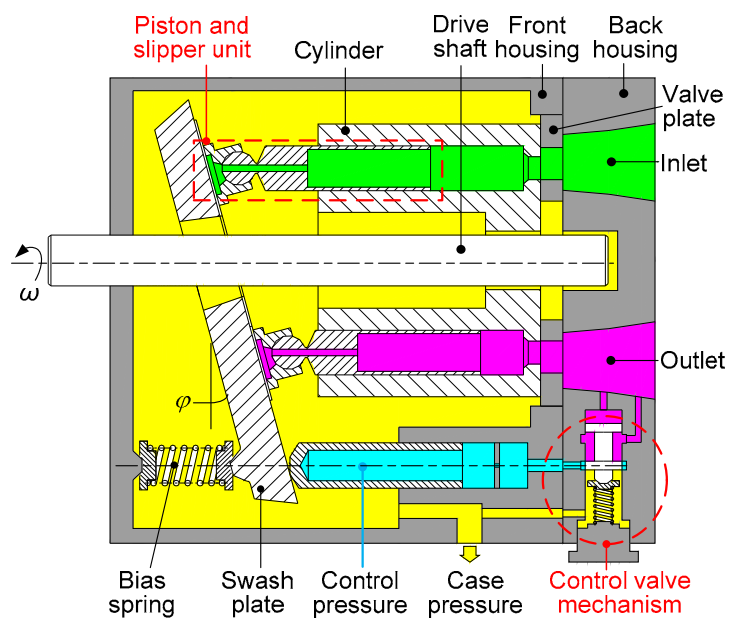

Fig. 1 Cross-section view of the pump 
volume of chambers, the orifices and the compressible oil, complicate the pump dynamic model immensely. There are obvious FSIs in the pump, where the motions of the rigid bodies compress the fluid, and then that fluid pressure fluctuation causes the rigid bodies to vibrate in turn. The transfer methods of mechanical vibration and fluid pressure force in conventional piston pump models are mostly unidirectional and separated. Based on the synthesized description of the structure of the pump, the block diagram of the pump is summarized in Fig. 2.

As shown in Fig. 2a, there are three main FSIs in the pump. The FSI-1 that contains the pistons and the variable piston chambers is the most complicated and important FIS in the pump. The velocity, displacement, and pressure of the pistons and chambers are different at any time. The flow fluctuation from the piston chamber can be divided into two parts. The first part is the kinematic flow fluctuation, which is due to the limited number of pistons and directly caused by their motions. The second part is the compressible flow fluctuation, which is caused by large alternating pressures in the valve plate. The FSI-2 contains the control actuator and the dynamic control chamber, whose main function is to adjust the swash plate at a suitable angle to meet the preset discharge pressure. Hence, the dynamic motion of the swash plate is greatly influenced by the FSI-2. The FSI-3, unit of the moving control valve spool, its variable chamber and variable opening, mainly affect the flow rate to the outlet chamber and the discharge pressure pulsation. Besides, the FSI-3 indirectly affects the pressure of the control actuator chamber and the vibration of the swash plate. The pistons, the control actuator, and the control valve, which are the key components of the three main FSIs, are simplified and their high-order dynamics are neglected in the non FSI model in Fig. 2b.

\subsection{Kinematic analysis}

The relative positions of the key components of FSI-1 are shown in Fig. 3. It can be seen that $X_{0} Y_{0} Z_{0}$ is the space-fixed reference frame assigned at the center of the pump, with its $Z_{0}$-axis pointing along the central axis of the drive shaft. The $X_{0}$-axis is vertical to the drive shaft and through the top dead center of the piston. The reference frame $X_{4} Y_{4} Z_{4}$ (with its $X_{4}$ and $Z_{4}$-axes pointing along the top-dead center and vertical to the motion plane of the piston spherical joints) is assigned at the intersection $\mathrm{O}_{4}$ of the shaft and the motion plane of the piston spherical joints. Hence,

(a)

$4--$ Fluid relation $\longleftarrow$ Structure relation

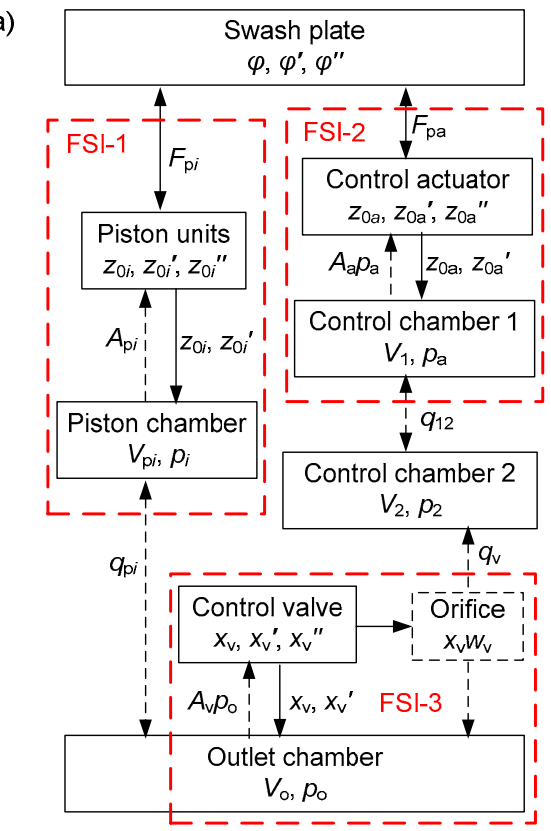

(b)

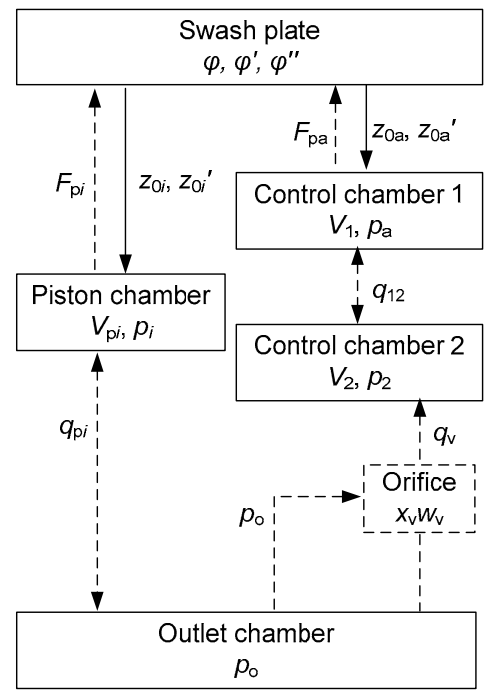

Fig. 2 Block diagram of the pump

(a) Full FSI model; (b) Non FSI model. $A_{\mathrm{v}}$ : the cross-sectional area of control valve spool; $F_{\mathrm{p} i}$ : the force from the swash plate to the $i$ th piston; $F_{\mathrm{pa}}$ : the force from the swash plate to the control actuator; $p_{\mathrm{a}}$ : the pressure in the control chamber $1 ; p_{2}$ : the pressure in the control chamber $2 ; p_{\mathrm{o}}$ : the pressure in the outlet chamber; $p_{i}$ : the pressure in the $i$ th piston chamber; $q_{12}$ : the flow rate between two control chambers; $q_{\mathrm{p} i}$ : the flow rate of the $i$ th piston; $q_{\mathrm{v}}$ : the flow rate of control valve; $V_{1}, V_{2}$ : the volume of the control chambers; $w_{\mathrm{v}}$ : the control valve spool perimeter; $x_{\mathrm{v}}$ : the control valve spool displacement; $z_{0 i}$ : the piston displacement; $z_{0 \mathrm{a}}$ : the control actuator displacement 


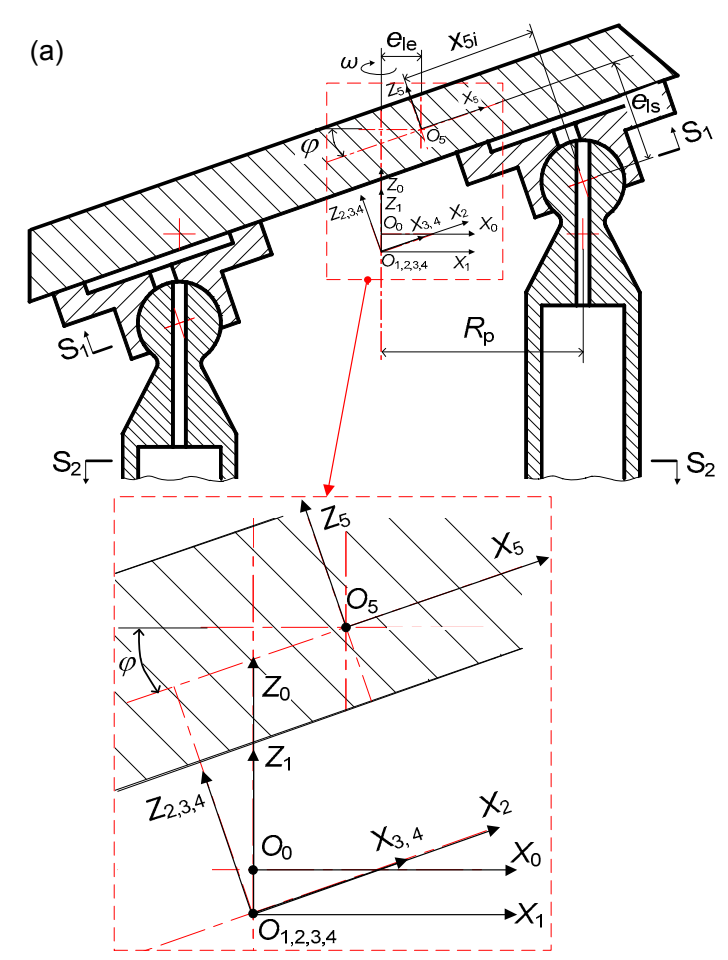

(b)

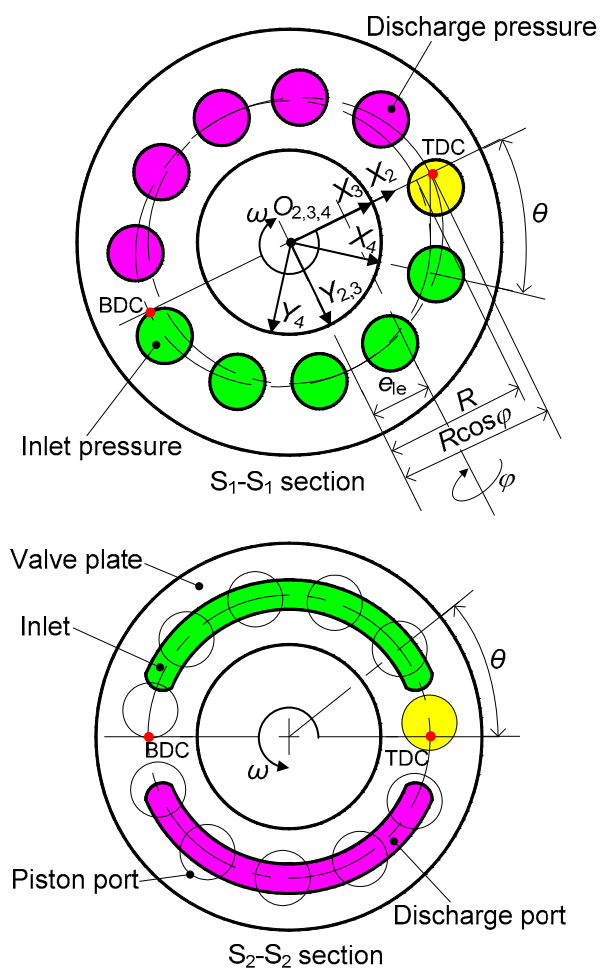

Fig. 3 Geometrical relationship in the pump

(a) Location of the coordinate systems; (b) Movement schematic of slipper shoes and pistons. BDC: bottom dead center; TDC: top dead center; $e_{\mathrm{le}}$ : the eccentricity between the drive shaft and the swash plate rotation axis; $e_{1 s}$ : the eccentricity between the center of the spherical joint and the swash plate rotation axis
$X_{4} Y_{4} Z_{4}$ coincides with $X_{0} Y_{0} Z_{0}$ when the inclinational angle $\varphi$ is zero, and the synthesized transformation matrix is ${ }_{4}^{0} \boldsymbol{T}$, where ${ }^{0} \boldsymbol{P}$ is the final position of the $i$ th piston transformed from ${ }^{4} \boldsymbol{P}$.

By analyzing the kinematic relations of the pump, as shown in Appendix A, the synthesized transformation matrix can be given as

$$
\begin{aligned}
{ }_{4}^{0} \boldsymbol{T} & ={ }_{1}^{0} \boldsymbol{T}_{2}^{1} \boldsymbol{T}_{3}^{2} \boldsymbol{T}_{4}^{3} \boldsymbol{T} \\
& =\left[\begin{array}{cccc}
\cos \theta & -\sin \theta & -\sin \varphi & 0 \\
\sin \theta & \cos \theta & 0 & 0 \\
\cos \theta \tan \varphi & -\sin \theta \tan \varphi & \cos \varphi & -e_{1} \\
0 & 0 & 0 & 1
\end{array}\right] .
\end{aligned}
$$

The final position of the $i$ th piston ${ }^{0} \boldsymbol{P}$ is

$$
{ }^{0} \boldsymbol{P}=\left[\begin{array}{c}
x_{i} \cos \theta-y_{i} \sin \theta-z_{i} \sin \varphi \\
x_{i} \sin \theta+y_{i} \cos \theta \\
-e_{1}+\tan \varphi\left(x_{i} \cos \theta-y_{i} \sin \theta\right)+z_{i} \cos \varphi \\
1
\end{array}\right]
$$

As a key mechanism of FISs, the torque on the swash plate can be transferred from the forces on the pistons at $X_{4} Y_{4} Z_{4}$ (with the synthesized transformation matrix $\left.{ }_{4}^{5} \boldsymbol{T}\right)$. The reference frame $X_{5} Y_{5} Z_{5}$ is assigned at the center $O_{5}$, with its $Y_{5}$-axis coinciding with the rotational axis of the swash plate, and $X_{5}$-axis and $Z_{5}$-axis parallel and vertical to the plane of the swash plate. ${ }^{5} \boldsymbol{P}$ is defined as the position of the piston at $X_{5} Y_{5} Z_{5}$. Hence, the lever arm length of each piston is equal to the coordinate value at the $X_{5}$-axis of ${ }^{5} \boldsymbol{P}$. The synthesized transformation matrix ${ }_{4}^{5} \boldsymbol{T}$ and the coordinate values of ${ }^{5} \boldsymbol{P}$ are given as

$$
\begin{aligned}
& { }_{4}^{5} \boldsymbol{T}={ }_{2}^{5} \boldsymbol{T}_{3}^{2} \boldsymbol{T}_{4}^{3} \boldsymbol{T}=\left[\begin{array}{cccc}
\frac{\cos \theta}{\cos \varphi} & -\frac{\sin \theta}{\cos \varphi} & 0 & -e_{2} \\
\sin \theta & \cos \theta & 0 & 0 \\
0 & 0 & 1 & -e_{\mathrm{ls}} \\
0 & 0 & 0 & 1
\end{array}\right], \\
& { }^{5} \boldsymbol{P}=\left[\begin{array}{c}
\left(x_{i} \cos \theta-y_{i} \sin \theta\right) / \cos \varphi-e_{2} \\
x_{i} \sin \theta+y_{i} \cos \theta \\
z_{i}-e_{1 \mathrm{~s}} \\
1
\end{array}\right]
\end{aligned}
$$




\subsection{Modeling the FSIs}

The dynamic FSIs in the pump are modeled as a system with lumped parameter nonlinear components of different energy subsystems. The swash plate angle and the outlet chamber pressure interact with each other through the three FSIs.

\subsubsection{Swash plate motion}

The position of the swash plate is defined by the bias actuator, the control actuator, the slippers, and the pistons, which are known as FSI-1 and FSI-2. The inclination $\varphi$ of the swash-plate (inertia $J_{\mathrm{s}}$ ) relative to the pump case is governed by the torques, $T_{0}, T_{\mathrm{a}}$, and $T_{\mathrm{p}}$, contributed by the pre-tightening force of the bias spring, control actuator, and the forces of the piston/ slipper units, respectively. The dynamic equation of the swash plate rotation (with damping coefficient $b_{\mathrm{s}}$ ) about the $Y_{5}$-axis is described by

$$
J_{\mathrm{s}} \ddot{\varphi}+b_{\mathrm{s}} \dot{\varphi}+x_{5 \mathrm{a}}^{2} k_{\mathrm{b}} \varphi=T_{\mathrm{p}}+T_{\mathrm{a}}+T_{0},
$$

where $x_{5 \mathrm{a}}$ is the position of the control actuator at the $X_{5}$-axis of the reference frame $X_{5} Y_{5} Z_{5}$, which is also identified as the moment arm of the control actuator pressure force relative to the rotation axis of the swash plate ( $Y_{5}$-axis). Once the average angle of the swash plate is stable, the average sum torque $T_{\mathrm{p}}$ from the pistons is constant. The actuator torque $T_{\mathrm{a}}$ is designed to counteract the piston torque $T_{\mathrm{p}}$ to balance the swash plate. Hence, the longer the moment arm, the less is the pressure force $F_{\mathrm{a}}$ of the control actuator. It means that a smaller area $A_{\mathrm{a}}$ or a lower actuator pressure $p_{\mathrm{a}}$ is needed. However, a longer moment arm may increase the bulk and weight of the pump.

\subsubsection{Outlet discharge pressure}

The fluid flowing in and out and the changing volume of the outlet chamber, which are the major parts of the FSI-2 and FSI-3, make the discharge pressure of the outlet chamber pulse rhythmically. As the outlet chamber $V_{\mathrm{o}}$ is a typical closed chamber, the discharge pressure $p_{0}$ can be calculated from Eq. (6). One proportional flow valve is used as the load, of which the flow rate gain factor is $c_{1}$. The transfer function of the output part is given as

$$
\frac{\mathrm{d} p_{\mathrm{o}}}{\mathrm{d} t}=\frac{K}{V_{\mathrm{o}}}\left(\sum_{i=1}^{n} q_{\mathrm{p} i}-c_{1} p_{\mathrm{o}}-Q_{\mathrm{v}}\right)
$$

where $K$ is the fluid bulk modulus, $q_{\mathrm{p} i}$ is the flow rate from the piston chamber to the outlet chamber of the $i$ th piston, and $Q_{\mathrm{v}}$ is the flow rate from the outlet chamber to the control chamber 2 .

\subsubsection{FSI-1: pistons}

The FSI-1 contains the motion of the pistons, the changing volumes and the pressure of the piston chambers. The swash plate and the outlet chamber are connected by FSI-1. The pistons move along the $Z_{0}$-axis following the oscillation of the swash plate. The moving pistons make the piston chambers take oil from the inlet chamber and discharge it to the outlet chamber. Conversely, the changing pressures of the piston chambers result in forces on the pistons, which cause the high frequency disturbed vibration of the swash plate.

The forces on one piston mainly consist of the pressure force, the reaction force from the slipper shoe, the inertial force, the damping force and friction. The force balance equation and the position of one piston at the $Z_{0}$-axis are given as follows:

$$
\begin{gathered}
m \ddot{z}_{0 i}+b_{i} \dot{z}_{0 i}=A p_{i}-F_{\mathrm{p} i} \pm f_{i}, \\
z_{0 i}=-e_{1}+\tan \varphi\left(x_{4 i} \cos \theta-y_{4 i} \sin \theta\right)+z_{4 i} \cos \varphi,
\end{gathered}
$$

where $m$ is the mass of one piston, $b_{i}$ is the damping coefficient of the $i$ th piston, $A$ is the pressure area of one piston, $p_{i}$ is the pressure of the $i$ th piston chamber, and $f_{i}$ is the sliding friction between the piston and the cylinder block. As a disturbing force, the friction $f_{i}$ is much lower than the pressure force on the piston and can be ignored. Therefore, the value of the friction in the simulation models can be set to zero. Hence, the total torque $T_{\mathrm{p}}$ on the swash plate of the pistons can be derived as

$$
T_{\mathrm{p}}=\sum_{i=1}^{n} x_{5 i}\left(A p_{i}-m \ddot{z}_{0 i}-b_{i} \dot{z}_{0 i} \pm f_{i}\right) / \cos \varphi,
$$

where $x_{5 i}$ is the position of the $i$ th piston at the $X_{5}$-axis of the reference frame $X_{5} Y_{5} Z_{5}$, which is also identified as the moment arm of one slipper shoe relative to the 
rotation axis of the swash plate ( $Y_{5}$-axis).

The velocity and acceleration of each piston can be obtained by a calculation of the first and second derivatives of Eq. (8). Thus, the acceleration of the piston can be split into two parts: one part contains the factor of the second derivative of $\varphi$ and the other does not. The total torque $T_{\mathrm{p}}$ can be calculated from Eqs. (8) and (9) as follows:

$$
\begin{aligned}
T_{\mathrm{p}}= & \sum_{i=1}^{n} x_{5 i}\left(A p_{i}-b_{i} \dot{z}_{0 i} \pm f_{i}\right) / \cos \varphi \\
& -\sum_{i=1}^{n} m_{\mathrm{p}} x_{5 i} \ddot{z}_{0 i a}(\varphi, \dot{\varphi}) / \cos \varphi \\
& -\ddot{\varphi} \sum_{i=1}^{n} m_{\mathrm{p}} x_{5 i} \ddot{z}_{0 i b}(\varphi, \dot{\varphi}) / \cos \varphi, \\
T_{\mathrm{pa}}= & \sum_{i=1}^{n} x_{5 i}\left(A p_{i}-b_{i} \dot{z}_{0 i} \pm f_{i}\right) / \cos \varphi \\
& -\sum_{i=1}^{n} m_{\mathrm{p}} x_{5 i} \ddot{z}_{0 i \mathrm{a}}(\varphi, \dot{\varphi}) / \cos \varphi,
\end{aligned}
$$

where $T_{\mathrm{pa}}$ is one part of the $T_{\mathrm{p}}$, which does not contain the second derivative of $\varphi$. The dynamic differential equation of the swash plate and piston oscillatory mechanism is modified from Eq. (5) as

$$
\begin{gathered}
{\left[J_{\mathrm{s}}+\sum_{i=1}^{n} J_{\mathrm{p} i}(\varphi, \dot{\varphi})\right] \ddot{\varphi}=T_{\mathrm{a}}+T_{0}+T_{\mathrm{pa}}-b_{\mathrm{s}} \dot{\varphi}-x_{5 i}^{2} k_{\mathrm{b}} \varphi,} \\
J_{\mathrm{p} i}(\varphi, \dot{\varphi})=m_{\mathrm{p}} x_{5 i} \ddot{z}_{0 i b}(\varphi, \dot{\varphi}) / \cos \varphi
\end{gathered}
$$

where $J_{\mathrm{p} i}$ is defined as the equivalent moment of inertia (rotational inertia) to the swash plate rotary axis $\left(Y_{5}\right.$-axis) of one piston.

The pressure of each piston chamber can be calculated by

$$
\frac{\mathrm{d} p_{\mathrm{p} i}}{\mathrm{~d} t}=\frac{K}{V_{\mathrm{p} i}}\left(-\dot{z}_{0 i} A_{\mathrm{p}}-q_{\mathrm{li}}+q_{\mathrm{i} i}-q_{\mathrm{o} i}\right)=\frac{K}{V_{\mathrm{p} i}} q_{\mathrm{p} i},
$$

where $q_{1 i}$ is the piston leakage flow, $q_{\mathrm{ii}}$ is the flow from the inlet port and $q_{\mathrm{o} i}$ is the flow to the discharge port. The leakage flow consists of three main parts: the first is the leakage passage between pistons and the cylinder, the second that between the cylinder and the valve plate, and the third that between the slipper shoes and the swash plate.
In the non FSI model, the dynamic motion of the piston is simplified compared with the full FSIs model. The velocity and acceleration of each piston are the first and second partial derivatives of the function Eq. (8) with respect to the variable $\theta$, assuming that $\varphi$ is a constant. Hence, the equivalent rotational inertia of the pistons is not considered and the motion in the non FSI model is simpler than the full FSIs model as follows:

$$
\begin{aligned}
\dot{z}_{0 i}= & \dot{\theta} \tan \varphi\left(-x_{4 i} \sin \theta-y_{4 i} \cos \theta\right), \\
\ddot{z}_{0 i}= & -x_{4 i} \tan \varphi\left(\ddot{\theta} \sin \theta+\dot{\theta}^{2} \cos \theta\right) \\
& -y_{4 i} \tan \varphi\left(\ddot{\theta} \cos \theta-\dot{\theta}^{2} \sin \theta\right) .
\end{aligned}
$$

\subsubsection{FSI-2: control actuator}

The control actuator connects the control valve to the swash plate throughout FSI-2. The FSI-2 contains the motion of the control actuator, the changing volumes, and the pressure of the control actuator chamber 1 . Similarly to the pistons, the control actuator moves along the $Z_{0}$-axis following the oscillation of the swash plate. The moving actuator piston makes the control chamber 1 charge/discharge oil from the control chamber 2. Conversely, the changing pressure of the chamber results in a changing force on the control actuator, which causes the high frequency disturbed vibration of the swash plate.

The forces on the control actuator are similar to those on the pistons in FSI-1 and can be given as follows:

$$
\begin{gathered}
m_{\mathrm{a}} \ddot{z}_{0 \mathrm{a}}+b_{\mathrm{a}} \dot{z}_{0 \mathrm{a}}=A_{\mathrm{a}} p_{\mathrm{a}}-F_{\mathrm{pa}} \pm f_{\mathrm{a}}, \\
z_{0 \mathrm{a}}=x_{5 \mathrm{a}} \tan \varphi,
\end{gathered}
$$

where $m_{\mathrm{a}}$ is the mass of the control actuator, $b_{\mathrm{a}}$ is the damping coefficient, $A_{\mathrm{a}}$ is the pressure area, $p_{\mathrm{a}}$ is the chamber pressure, $f_{\mathrm{a}}$ is the sliding friction, and $z_{0 \mathrm{a}}$ is the control actuator displacement. Hence, the torque $T_{\mathrm{a}}$ on the swash plate of the control actuator can also be derived as

$$
T_{\mathrm{a}}=\left(A_{\mathrm{a}} p_{\mathrm{a}}-m_{\mathrm{a}} \ddot{z}_{0 \mathrm{a}}-b_{\mathrm{a}} \dot{z}_{0 \mathrm{a}} \pm f_{\mathrm{a}}\right) x_{5 \mathrm{a}} / \cos ^{2} \varphi .
$$

Similarly, we can obtain Eqs. (20)-(23) from Eqs. (10)-(13) as follows: 


$$
\begin{aligned}
& T_{\mathrm{a}}=\left(A_{\mathrm{a}} p_{\mathrm{a}}-b_{\mathrm{a}} \dot{z}_{0 \mathrm{a}} \pm f_{\mathrm{a}}\right) x_{5 \mathrm{a}} / \cos ^{2} \varphi \\
&-m_{\mathrm{a}} \ddot{z}_{0 \mathrm{aa}}(\varphi, \dot{\varphi}) x_{5 \mathrm{a}} / \cos ^{2} \varphi \\
&-\ddot{\varphi} m_{\mathrm{a}} \ddot{z}_{0 \mathrm{ab}}(\varphi, \dot{\varphi}) x_{5 \mathrm{a}} / \cos ^{2} \varphi, \\
& T_{\mathrm{aa}}=\left(A_{\mathrm{a}} p_{\mathrm{a}}-b_{\mathrm{a}} \dot{z}_{0 \mathrm{a}} \pm f_{\mathrm{a}}\right) x_{5 \mathrm{a}} / \cos ^{2} \varphi \\
&-m_{\mathrm{a}} \ddot{z}_{0 \mathrm{aa}}(\varphi, \dot{\varphi}) x_{5 \mathrm{a}} / \cos ^{2} \varphi, \\
& {\left[J_{\mathrm{s}}\right.}\left.\sum_{i=1}^{n} J_{\mathrm{p} i}(\varphi, \dot{\varphi})+J_{\mathrm{a}}(\varphi, \dot{\varphi})\right] \ddot{\varphi} \\
&= T_{0}+T_{\mathrm{aa}}+T_{\mathrm{pa}}-b_{\mathrm{s}} \dot{\varphi}-x_{5 \mathrm{a}}^{2} k_{\mathrm{b}} \varphi, \\
& J_{\mathrm{a}}(\varphi, \dot{\varphi})=m_{\mathrm{a}} \ddot{z}_{0 \mathrm{ab}}(\varphi, \dot{\varphi}) x_{5 \mathrm{a}} / \cos ^{2} \varphi,
\end{aligned}
$$

where $T_{\text {aa }}$ is one part of the $T_{\mathrm{a}}$, which does not contain the second derivative of $\varphi . J_{\mathrm{a}}$ is defined as the equivalent moment of inertia (rotational inertia) to the swash plate rotary axis ( $Y_{5}$-axis) of the control actuator. As a disturbing force, the friction $f_{\mathrm{a}}$ is much lower than the pressure force on the control actuator and can be ignored. Therefore, the value of the friction in the simulation models was set to zero.

In the non FSI model, the inertial force of the control actuator is neglected and the equivalent rotational inertia of the control actuator is simplified as an approximate constant.

\subsubsection{FSI-3: control valve}

The dynamics of the control valve mechanism contain complex FSIs, FSI-3, which connect the outlet chamber to the control chamber 2 as shown in Fig. 4. The control valve turns the discharge pressure to the displacement of the spool, which causes the flow rate through the valve port and the outlet volume to change. The pressure of the chamber $V_{2}$ changes with the oil flow, and leads to a pressure difference with the chamber $V_{1}$. The feedback loop driven by the control valve and the bias actuator keeps the discharge pressure at a certain value changing with the load. The orifice between the control valve and the bias actuator can increase the damping of the bias actuator and stabilize the motion of the swash plate.

The motion equation of the control valve is given as

$$
m_{\mathrm{v}} \ddot{x}_{\mathrm{v}}+b_{\mathrm{v}} \dot{x}_{\mathrm{v}}+k_{\mathrm{v}} x_{\mathrm{v}}=p_{\mathrm{o}} A_{\mathrm{v}}-F_{0}-F_{\mathrm{d}} .
$$

The flow force, $F_{\mathrm{d}}$, has the same direction as the spring force. Near the balance position, the pressure pulsation and the displacement of the valve spool are both small. In this case, the flow force is much lower than the pressure force and can be ignored. Therefore, the valve spool is considered as a simple mass-springdamper system.

In the non FSI model, the inertial force of the control valve, the flow rate through the valve and the volume change of the outlet chamber are all neglected.

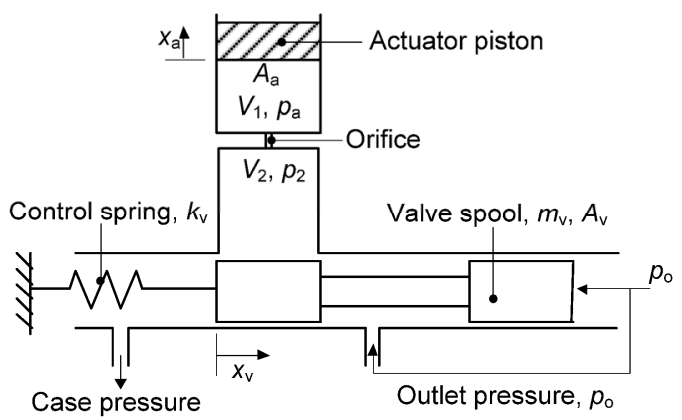

Fig. 4 Schematic of the control valve mechanism

\section{Discussion}

To evaluate the actual output performance of the piston pump, a test rig was built so that the simulation model could also be validated experimentally. Considering that the rated speed of the aircraft pump is 3000-4500 r/min, two sets of experimental results of discharge pressure were obtained at $4200 \mathrm{r} / \mathrm{min}$ and $3500 \mathrm{r} / \mathrm{min}$, at $100 \mathrm{~L} / \mathrm{min}$ and $28 \mathrm{MPa}$.

Fig. 5 shows the test rig. A throttle valve is used to simulate the hydraulic load. A high frequency pressure transducer is located at the pump outlet to measure the pressure fluctuation. The measure accuracy is over $0.1 \% \mathrm{FS}$, and the temperature drifting is less than $0.01 \% \mathrm{FS} /{ }^{\circ} \mathrm{C}$. The pump is driven by an inverter motor, and its rotation speed can be changed from 0 to $5000 \mathrm{r} / \mathrm{min}$. The values of specific parameters in this investigation are given in Table 1.

\subsection{Comparisons of experiment and simulation}

The experimental and simulated discharge pressure of the pump at $4200 \mathrm{r} / \mathrm{min}$ and $3500 \mathrm{r} / \mathrm{min}$ is given in Fig. 6 (p.210):

1. The pressure curves of the full FSIs model and the experiment coincide well with each other. In Fig. 6a, the discharge pressure pulsation amplitude of the experiment result is about $1.7 \mathrm{MPa}$ at $4200 \mathrm{r} / \mathrm{min}$ 
and the simulation result is $1.8 \mathrm{MPa}$, a little higher. The simulation error of pressure pulsation is thus about $5.9 \%$. At $3500 \mathrm{r} / \mathrm{min}$, as shown in Fig. $6 \mathrm{~b}$, the experimental pulsation is $1.3 \mathrm{MPa}$ and the simulation pulsation is $1.2 \mathrm{MPa}$ at $3500 \mathrm{r} / \mathrm{min}$. The simulation error is $7.7 \%$, which is greater than that at $4200 \mathrm{r} / \mathrm{min}$.
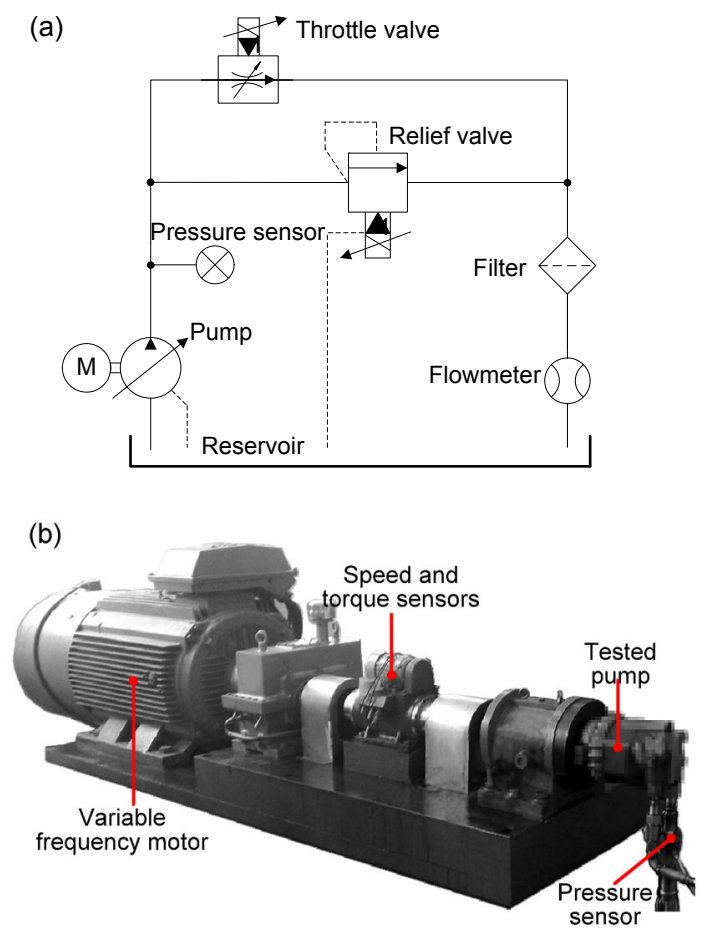

Fig. 5 Schematic (a) and photo (b) of the test rig

Table 1 Parameters of pump and test rig

\begin{tabular}{lc}
\hline \multicolumn{1}{c}{ Parameter } & Value \\
\hline Pump & 28 \\
Discharge pressure, $p_{\mathrm{o}}(\mathrm{MPa})$ & $3000-4500$ \\
Rated speed range $(\mathrm{r} / \mathrm{min})$ & 19 \\
Piston diameter, $d_{\mathrm{p}}(\mathrm{mm})$ & 45 \\
Piston rotation radius, $r_{\mathrm{pc}}(\mathrm{mm})$ & 4.0 \\
Valve diameter, $d_{\mathrm{v}}(\mathrm{mm})$ & 110 \\
Valve spring stiffness, $k_{\mathrm{v}}(\mathrm{N} / \mathrm{mm})$ & 5.5 \\
Valve spool mass, $m_{\mathrm{v}}(\mathrm{g})$ & 17.0 \\
Bias spring stiffness, $k_{\mathrm{b}}(\mathrm{N} / \mathrm{mm})$ & 0.0046 \\
Swash plate moment of inertia, $J_{\mathrm{s}}\left(\mathrm{kg} \cdot \mathrm{m}^{2}\right)$ & \\
\hline Test rig & 0.5 \\
Inlet pressure $(\mathrm{MPa})$ & 900 \\
Oil density, $\rho\left(\mathrm{kg} / \mathrm{m}^{3}\right)$ & 1100 \\
Oil bulk modulus, $K(\mathrm{MPa})$ & $40-50$ \\
Oil temperature $\left({ }^{\circ} \mathrm{C}\right)$ & $1.5 \times 10^{-5}$ \\
Oil kinematic viscosity, $v\left(\mathrm{~m}^{2} / \mathrm{s}\right)$ & 5000 \\
Sampling frequency $(\mathrm{Hz})$ &
\end{tabular}

2. The good agreement between the experimental and theoretical results at different rotation speeds proves that the full FSIs pump model can predict the pump state very well. Thus, the pump model can be used to describe other parameters of the pump that are difficult to measure.

\subsection{Relationship of discharge pressure and swash plate angle}

As shown in Fig. 6, the result curves of the full FSIs model and the non FSI model are mostly similar except in respect of the average value of amplitude. The peak-to-peak value of the full FSIs model, $1.8 \mathrm{MPa}$, is about 1.5 times the value of the non FSI model at $4200 \mathrm{r} / \mathrm{min}$, and it is about 1.1 times at $3500 \mathrm{r} / \mathrm{min}$. The average value of the full FSIs model is about $0.5 \mathrm{MPa}$ lower than the non FSI model at both speeds. Fig. $6 \mathrm{c}$ shows that the frequency components of the pressure pulsation of the two models are almost the same. The high degree of similarity between the results of the two models reflects that both models have similar accuracy in terms of simulating the pressure pulsation of the piston pump. Many previous studies had good agreement between their experiments and simulation results when the simulation models did not contain one or two of the three FSIs.

The angle of the swash plate is shown in Figs. 7a and $7 \mathrm{~b}$. The amplitude of the vibration angle of the full FSIs model is much less than the non FSI model at $3500 \mathrm{r} / \mathrm{min}$, which is even more obvious at $4200 \mathrm{r} / \mathrm{min}$. Moreover, the amplitude at $3500 \mathrm{r} / \mathrm{min}$ is less than that at $4200 \mathrm{r} / \mathrm{min}$, which means that the higher the rotation speed, the more violent the swash plate vibration. As shown in Fig. 7c, the amplitude of the second harmonic is much higher than the fundamental frequency of the full FSIs model at 4200 $\mathrm{r} / \mathrm{min}$, whereas the opposite is true in the non FSI model. However, the frequency components of the two models are very similar at $3500 \mathrm{r} / \mathrm{min}$. Obviously, there are wide differences in predicting the vibration of the swash plate between the two models, and the result of the full FSIs model is more credible because it is the more complete model. Therefore, the full FSIs model is necessary for analysis of the relation between the swash plate vibration and the pressure pulsation. 

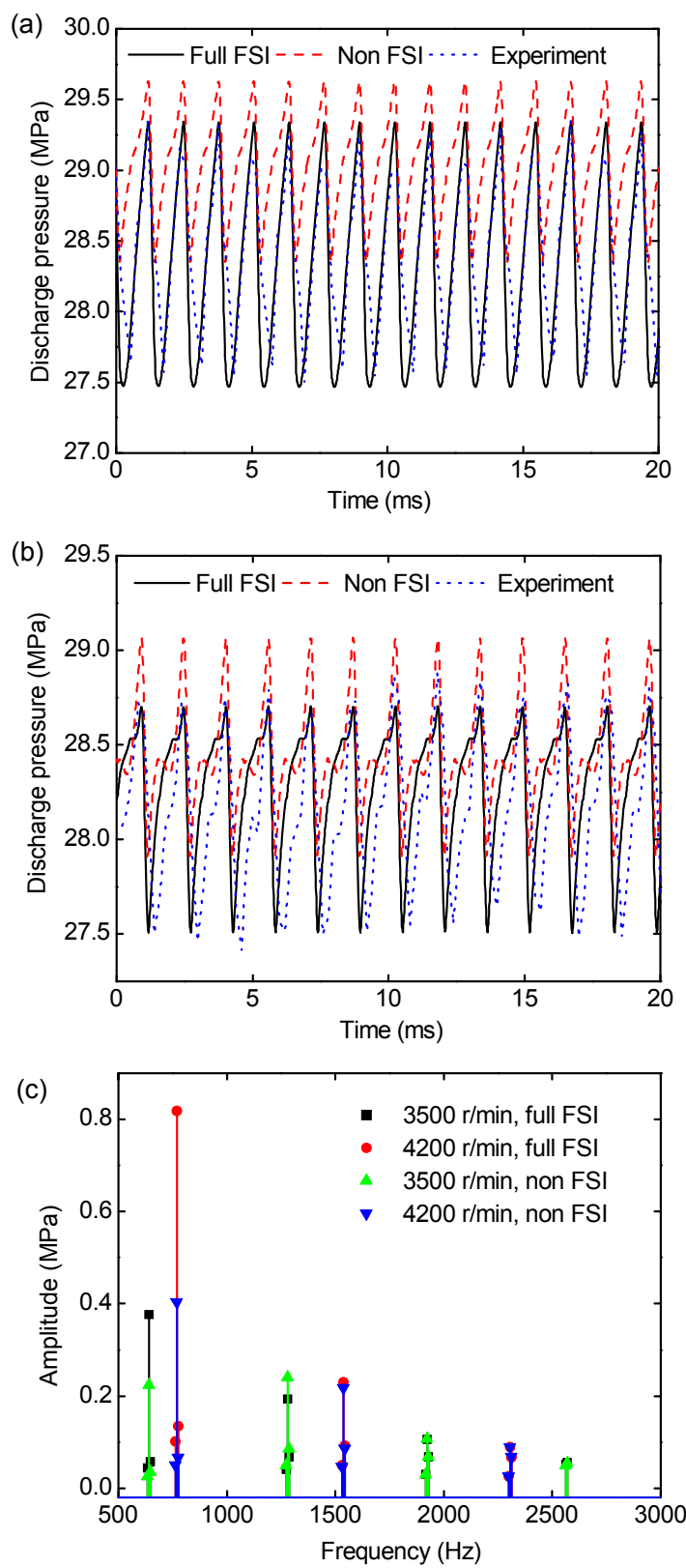

Fig. 6 Discharge pressure pulsation

(a) The discharge pressure pulsation at $4200 \mathrm{r} / \mathrm{min}$; (b) The discharge pressure pulsation at $3500 \mathrm{r} / \mathrm{min}$; (c) The spectrum graph of the discharge pressure pulsation

\subsection{Relation between pressure pulsation and angle vibration}

The discharge pressure depends upon the flow rate of the chamber shown in Fig. 8. There are three concave peaks of each flow rate from the pistons $\left(Q_{\mathrm{p}}\right)$ as follows: peak-1 is larger than the others because of
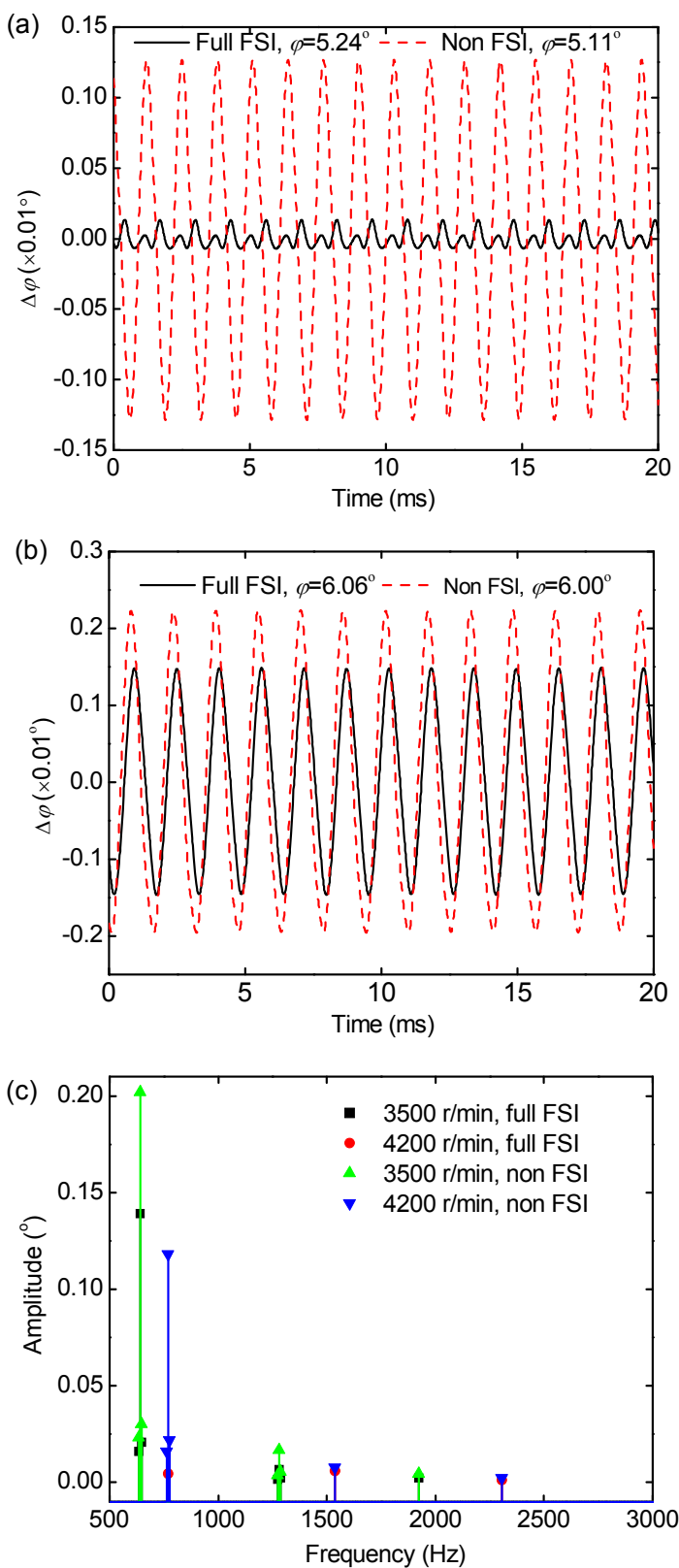

Fig. 7 Dynamic angle of the swash plate

(a) The angle of the swash plate at $4200 \mathrm{r} / \mathrm{min}$; (b) The angle of the swash plate at $3500 \mathrm{r} / \mathrm{min}$; (c) The spectrum graph of the swash plate angle

the backflow when the piston chamber starts to connect to the discharge area; peak- 2 is caused by the piston starting to suck oil when it is still connected to the discharge region; peak- 3 is the inherent characteristic of the pump which has odd numbered pistons. The result of the full FSIs model is a little larger than for the non FSI model. The flow rate $\left(Q_{\mathrm{v}}\right)$ of the 
control valve based on the full FSIs model contains positive values, for the flow rate caused by the spool movement is considered in FSI-2. However, the largest difference between the two models concerns different phases of the flow rate from the control valve. The phase of the non FSI result has a fixed phase difference with the discharge pressure, whereas there are different phase changes of the full FSIs results at different rotation speeds. Considering the control valve mechanism as a second-order dynamic system, the response of the system, such as the outward flow rate, depends upon its inherent characteristics and the frequency of the input signal. Moreover, the control valve flow rate of the full FSIs model is larger than that of the non FSI model. Therefore, it is enough to affect the piston flow rate, and hence, the discharge pressure. The flow rate through the control valve directly influences the pressures in the control chambers, and thus the vibration of the swash plate, as will be shown.

(a)

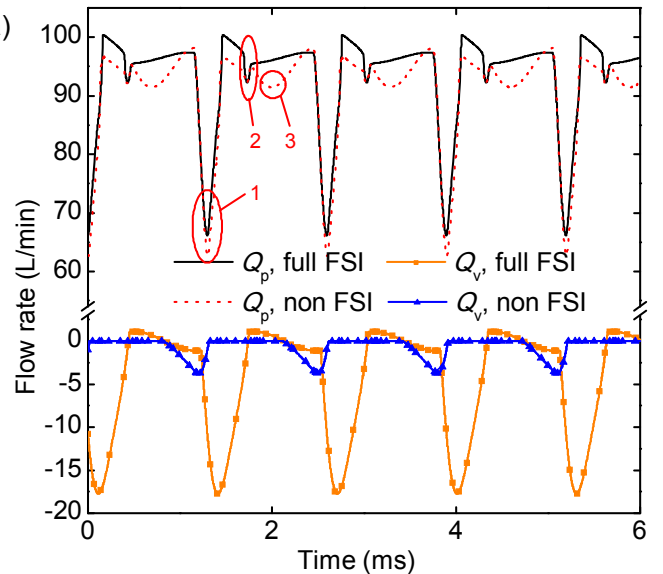

(b)

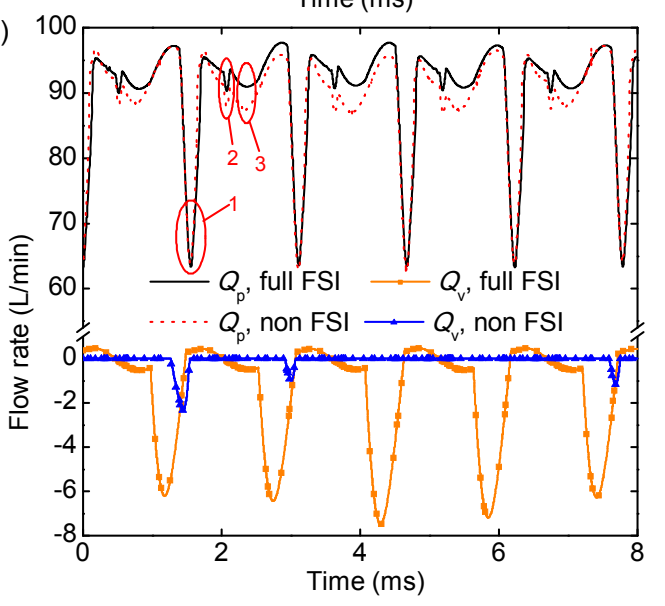

Fig. 8 Flow rate of the outlet chamber at the rotation speed of $4200 \mathrm{r} / \mathrm{min}$ (a) and $3500 \mathrm{r} / \mathrm{min}(\mathrm{b})$
The torque on the swash plate is shown in Fig. 9. Basically, the torque from the pistons magnifies the swash plate angle $(\varphi)$ and the torque from the control actuator does the opposite. The piston torque contains two main parts: the frequency of the piston motion and its second harmonic. As shown in Fig. 7, the amplitude of the angle in the non FSI results is larger than that in the full FSIs results, and so is the torque from the pistons. However, the torque from the control actuator of the full FSIs contrasts greatly to that in the non FSI results. Because of the orifice between the two control chambers, the changed phase of the control signal is delayed again. As a result of the differential phase shift changes of the control torque at different speeds, the vibration of the swash plate shows significant difference at different speeds. Therefore, it can be stated that the basic components of the swash plate vibration depend upon the torque of the pistons, which originates from the pulsating pressure through FSI-1, and the final vibration type depends upon the control torque, which originates from the pulsating pressure through FSI-3 and FSI-2.
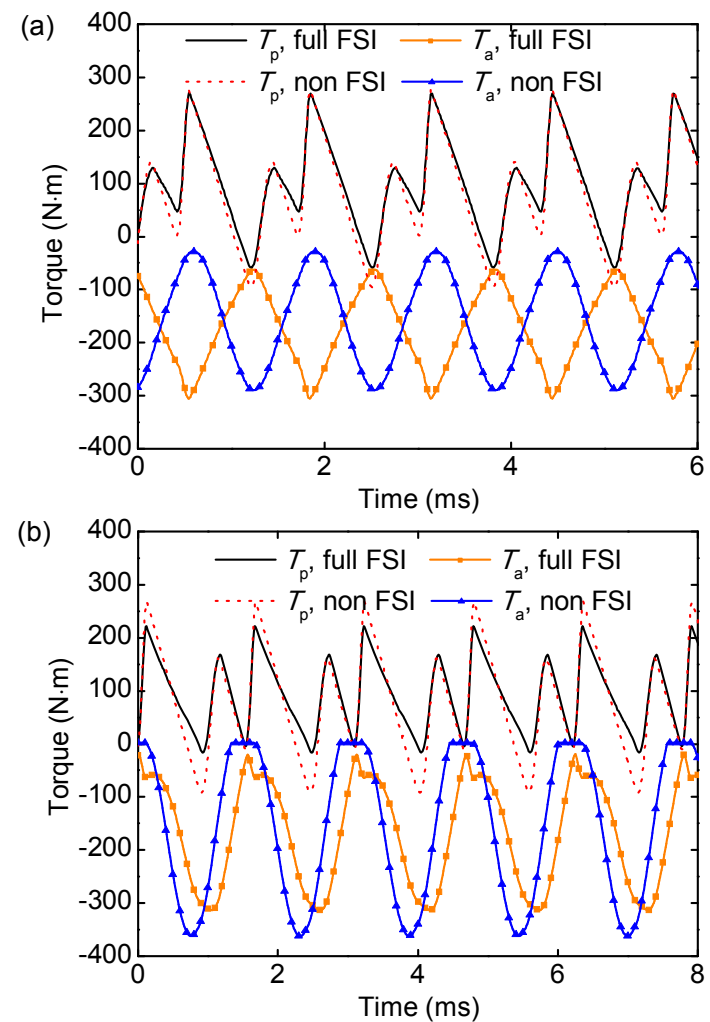

Fig. 9 Torques on the swash plate at the rotation speed of $4200 \mathrm{r} / \mathrm{min}$ (a) and $3500 \mathrm{r} / \mathrm{min}$ (b) 
Fig. 10 shows that the pressure pulsation and the angle oscillation change with rotation speed. The oscillation amplitude of the swash plate angle decreases steadily with increased rotation speed, except near $4200 \mathrm{r} / \mathrm{min}$. As has been analyzed, because the phase difference between the piston torque and the actuator torque is about $180^{\circ}$, the angle vibration reaches a minimum at about $4200 \mathrm{r} / \mathrm{min}$. The pressure pulsation reaches a maximum at a speed near $4050 \mathrm{r} / \mathrm{min}$, because the flow rate of the control valve reaches a maximum near the resonance frequency of the control valve.

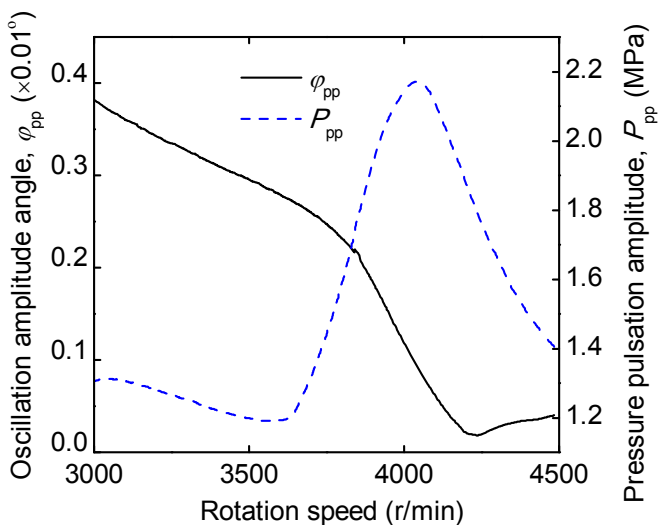

Fig. 10 The peak-to-peak value of pressure pulsation and angle vibration at different rotation speeds

In summary, the full FSIs model is much more accurate than the non FSI model in simulating the relation between the swash plate vibration and the pressure pulsation of the aircraft piston pump. The FSI-1 is mostly bidirectional from the pressure pulsation to the swash plate vibration and from the swash plate vibration to the pressure pulsation. Thus, the basic vibration type of the swash plate is defined by the FSI-1. The FSI-2 and FSI-3 are unidirectional from the pressure pulsation to the swash plate vibration. The discharge pressure pulsation affects the flow rate of the control valve; hence, the movement of the control pressure, the control torque and the swash plate.

There are, therefore, some efficient ways to reduce the vibration of the swash plate, such as modifying the geometrical parameters of the swash plate mechanism, the control valve mechanism and the orifice, which means optimizing their natural frequency and damping. Furthermore, making the pump work at an optimized rotation speed range can also minimize the vibration of the swash plate, and even decrease the pressure pulsation.

\section{Conclusions}

The dynamic analysis of the swash plate vibration and pressure pulsation of an aircraft piston pump based on FSIs is presented. Several conclusions can be drawn:

1. The full FSIs model is much more accurate in predicting the vibration of the swash plate and the pulsation of the discharge pressure than the non FSIs model.

2. The swash plate vibration is strongly influenced by the pressure pulsation through the control actuator mechanism (FSI-2) and the control valve mechanism (FSI-3). The discharge pressure pulsation is mostly dictated by the kinematic relations of the piston slipper-shoe units (FSI-1), and is almost isolated from the swash plate vibration.

\section{References}

Abuhaiba, M., Olson, W.W., 2010. Geometric and kinematic modeling of a variable displacement hydraulic bent-axis piston pump. Journal of Computational and Nonlinear Dynamics, 5(4):041010. http://dx.doi.org/10.1115/1.4002084

Bahr, M.K., Svoboda, J., Bhat, R.B., 2003. Vibration analysis of constant power regulated swash plate axial piston pumps. Journal of Sound and Vibration, 259(5): 1225-1236. http://dx.doi.org/10.1006/jsvi.2002.5231

Bergada, J.M., Davies, D.L., Kumar, S., et al., 2012. The effect of oil pressure and temperature on barrel film thickness and barrel dynamics of an axial piston pump. Meccanica, 47(3):639-654. http://dx.doi.org/10.1007/s11012-011-9472-7

Chen, H.X., Chua, P.S., Lim, G.H., 2006. Dynamic vibration analysis of a swash-plate type water hydraulic motor. Mechanism and Machine Theory, 41(5):487-504. http://dx.doi.org/10.1016/j.mechmachtheory.2005.09.002

Huang, J., Yan, Z., Quan, L., et al., 2015. Characteristics of delivery pressure in the axial piston pump with combination of variable displacement and variable speed. Proceedings of the Institution of Mechanical Engineers, Part I: Journal of Systems and Control Engineering, 229(7): 599-613. http://dx.doi.org/10.1177/0959651815578967

Johnston, D.N., Drew, J.E., 1996. Measurement of positive displacement pump flow ripple and impedance. Proceedings of the Institution of Mechanical Engineers, Part I: Journal of Systems and Control Engineering, 210(1): 65-74. 
Koralewski, J., 2011. Influence of hydraulic oil viscosity on the volumetric losses in a variable capacity piston pump. Polish Maritime Research, 18(3):55-65. http://dx.doi.org/10.2478/v10012-011-0018-7

Manring, N.D., 2000. The discharge flow ripple of an axialpiston swash-plate type hydrostatic pump. Journal of Dynamic Systems, Measurement, and Control, 122(2): 263-268. http://dx.doi.org/10.1115/1.482452

Manring, N.D., Mehta, V.S., 2011. Physical limitations for the bandwidth frequency of a pressure controlled, axialpiston pump. Journal of Dynamic Systems, Measurement, and Control, 133(6):061005. http://dx.doi.org/10.1115/1.4004056

Meher, K.K., Rao, A.R., 2006. Optimal foundation design of a vertical pump assembly. Journal of Sound and Vibration, 291(3-5):1269-1277. http://dx.doi.org/10.1016/j.jsv.2005.07.034

Norhirni, M.Z., Hamdi, M., Musa, S.N., et al., 2011. Load and stress analysis for the swash plate of an axial piston pump/motor. Journal of Dynamic Systems, Measurement, and Control, 133(6):064505. http://dx.doi.org/10.1115/1.4004578

Wang, L., Johnston, D.N., 2009. Narrow-band fluid borne noise attenuation using time-domain online control algorithms in a simple hydraulic system. 7th International Conference on Fluid Power Transmission and Control (ICFP 2009), University of Bath, UK.

$\mathrm{Xu}, \mathrm{B} .$, Lee, K.M., Song, Y., et al., 2015a. A numerical and experimental investigation of parametric effect on flow ripple. Proceedings of the Institution of Mechanical Engineers, Part C: Journal of Mechanical Engineering Science, 299(16):2939-2951. http://dx.doi.org/10.1177/0954406214564585

Xu, B., Sun, Y.H., Zhang, J.H., et al., 2015b. A new design method for the transition region of the valve plate for an axial piston pump. Journal of Zhejiang UniversitySCIENCE A (Applied Physics \& Engineering), 16(3): 229-240. http://dx.doi.org/10.1631/jzus.A1400266

Yang, H.Y., Pan, M., 2015. Engineering research in fluid power: a review. Journal of Zhejiang UniversitySCIENCE A (Applied Physics \& Engineering), 16(6): 427-442.

http://dx.doi.org/10.1631/jzus.A1400284

\section{Appendix A: Coordinates relations}

The relations between the coordinates can be summarized as follows. The coordinate $X_{1} Y_{1} Z_{1}$ is moved a distance $e_{1}$ along the $Z_{1}$-axis from the coordinate $X_{0} Y_{0} Z_{0}$ with the transformation matrixes ${ }_{1}^{0} \boldsymbol{T}$.
The transformation matrixes ${ }_{2}^{1} \boldsymbol{T}$ of the inclination of the swash plate can be treated as a rotation angle $-\varphi$ from the coordinate $X_{1} Y_{1} Z_{1}$ at $Y_{1}$-axis to the coordinate $X_{2} Y_{2} Z_{2}$. After the rotation transformation, the coordinate $X_{3} Y_{3} Z_{3}$ is scaled at $X_{2}$-axis to the coordinate $X_{2} Y_{2} Z_{2}$ with the transformation matrixes ${ }_{3}^{2} \boldsymbol{T}$. The reference frame $X_{3} Y_{3} Z_{3}$ is fixed to the cylinder block. Hence, there is a rotation angle $\theta$ by the $Z_{3}$-axis between $X_{3} Y_{3} Z_{3}$ and $X_{4} Y_{4} Z_{4}$ which has a transformation matrix ${ }_{4}^{3} \boldsymbol{T}$. The reference frame $X_{5} Y_{5} Z_{5}$ can be transformed to the reference frame $X_{2} Y_{2} Z_{2}$ by translation transformation matrix ${ }_{2}^{5} \boldsymbol{T}$, which are two displacements, $e_{2}$ along the $X_{2}$-axis and $e_{1 \mathrm{~s}}$ along the $Z_{2}$-axis.

The transformation matrixes, ${ }_{1}^{0} \boldsymbol{T},{ }_{2}^{1} \boldsymbol{T},{ }_{3}^{2} \boldsymbol{T},{ }_{4}^{3} \boldsymbol{T}$, and ${ }_{2}^{5} \boldsymbol{T}$ are given as

$$
\begin{aligned}
& { }_{1}^{0} \boldsymbol{T}=\left[\begin{array}{cccc}
1 & 0 & 0 & 0 \\
0 & 1 & 0 & 0 \\
0 & 0 & 1 & -e_{1} \\
0 & 0 & 0 & 1
\end{array}\right], \\
& { }_{2}^{1} \boldsymbol{T}=\left[\begin{array}{cccc}
\cos (-\varphi) & 0 & \sin (-\varphi) & 0 \\
0 & 1 & 0 & 0 \\
-\sin (-\varphi) & 0 & \cos (-\varphi) & 0 \\
0 & 0 & 0 & 1
\end{array}\right] \text {, } \\
& { }_{3}^{2} \boldsymbol{T}=\left[\begin{array}{cccc}
1 / \cos \varphi & 0 & 0 & 0 \\
0 & 1 & 0 & 0 \\
0 & 0 & 1 & 0 \\
0 & 0 & 0 & 1
\end{array}\right], \\
& { }_{4}^{3} \boldsymbol{T}=\left[\begin{array}{cccc}
\cos \theta & -\sin \theta & 0 & 0 \\
\sin \theta & \cos \theta & 0 & 0 \\
0 & 0 & 1 & 0 \\
0 & 0 & 0 & 1
\end{array}\right], \\
& { }_{2}^{5} \boldsymbol{T}=\left[\begin{array}{cccc}
1 & 0 & 0 & -e_{2} \\
0 & 1 & 0 & 0 \\
0 & 0 & 1 & -e_{1 \mathrm{~s}} \\
0 & 0 & 0 & 1
\end{array}\right], \\
& e_{1}=e_{\mathrm{le}} \tan \varphi+e_{\mathrm{ls}} \frac{1-\cos \varphi}{\cos \varphi}, \\
& e_{2}=\frac{e_{\mathrm{le}}}{\cos \varphi}+e_{\mathrm{ls}} \tan \varphi \text {. }
\end{aligned}
$$




\section{中文概要}

题 目: 基于流构全耦合模型的柱塞百斜盘振动和压力脉 动的研究

目 的：航空柱塞泵是飞机液压系统的核心元件, 具有高 压高转速的特点, 其压力脉动是飞机液压系统振 动的主要激励源, 对飞机液压系统的安全性和可 靠性具有重要影响。本文首次全面分析了压力脉 动和斜盘振动之间的关系, 对降低柱塞百的压力 脉动、提高其可靠性具有重要理论意义。

创新点: 1. 将柱塞洜压力脉动和斜盘振动相结合, 综合分 析两者相互作用关系; 2. 综合分析柱塞、斜盘控 制阀、斜盘控制柱塞三者间的作用关系，建立全 耦合模型。通过仿真分析和实验验证，指出普通 模型的局限性以及全耦合模型在研究斜盘振动 与压力脉动的真实内在关系的可靠性。
方 法: 1. 通过仿真和试验对比, 分析全耦合模型和普通 模型在压力脉动仿真结果上的差别及原因; 2 . 通 过对比分析, 确定全耦合模型在斜盘振动仿真方 面具有的较高精度; 3 . 通过柱塞泵高压腔流量仿 真结果, 讨论柱塞泵压力脉动成因以及与斜盘的 振动关系; 4. 通过斜盘力矩仿真分析讨论斜盘振 动成因以及与压力脉动的关系; 5 . 通过分析压力 脉动、斜盘振动和转速三者间的关系, 探讨减轻 斜盘振动与减小压力脉动的有效途径。

结 论: 1. 全耦合模型的精确度比普通模型高, 能较好地 预测斜盘振动和压力脉动状态。2. 斜盘振动的基 频部分主要取决于压力脉动的动态特性, 同时还 受控制阀机构 (FSI-3) 和变量柱塞机构 (FSI-2) 的动态特性影响。压力脉动主要由柱塞洜的柱塞 运动关系 (FSI-1) 决定, 不受斜盘高频振动影响。

关键词: 振动; 脉动; 斜盘; 航空; 柱塞洜; 流构耦合 